DOI 10.31418/2177-2770.2020.v12.n.34.p13-31 | ISSN 2177-2770

Licenciado sob uma Licença Creative Commons

\title{
ANDRELINO CAMPOS - DO QUILOMBO À FAVELA, DO ESPAÇO PERIFÉRICO SEGREGADO À TEORIA DO SUJEITO E A ANÁLISE DO LUGAR DO NEGRO NA SEGREGAÇÃO SOCIALMENTE INDUZIDA
}

Catia Antonia da Silva ${ }^{1}$

\begin{abstract}
Resumo: O presente artigo vem contribuir por meio de reflexão sobre estudos do geógrafo brasileiro Andrelino Campos, que foi professor Adjunto do Departamento de Geografia da Faculdade de Formação de professores da Universidade do Estado do Rio de Janeiro. Brasileiro, negro e oriundo da classe popular, foi grande pesquisador. Erudito, estudioso e muito criativo, tinha a sabedoria dos mestres e a capacidade de observação e de trabalho muito raro na academia. Considero um grande pensador dos tempos atuais e trouxe grandes contribuições à produção geográfica. Neste artigo, apresentamos duas seções. A primeira analisa as trajetórias de trabalho sobre a espacialidade do negro na produção da segregação socioespacial em São Gonçalo - município periférico da metrópole do Rio de Janeiro. Na segunda seção, apresenta considerações reflexivas do autor sobre o movimento social negro, utilizando ferramentas filosóficas para a compreensão das formas de resistências em contextos urbanos e societários.
\end{abstract}

Palavras-chave: segregação socioespacial, Geografia, movimento negro, cidade.

\section{ANDRELINO CAMPOS - FROM THE QUILOMBO TO THE FAVELA, FROM THE SEGREGATED PERIPHERAL SPACE TO THE THEORY OF THE SUBJECT AND THE ANALYSIS OF THE PLACE OF THE BLACK IN SOCIALLY INDUCED SEGREGATION}

\begin{abstract}
This article contributes through reflection on studies by the Brazilian geographer Andrelino Campos, who was an Adjunct Professor in the Department of Geography at the Faculty of Teacher Education at the State University of Rio de Janeiro. Brazilian, black and from the popular class, he was a great researcher. Scholarly, studious and very creative, he had the wisdom of the masters and the ability to observe and work very rarely in the academy. A great thinker of the present times, he made great contributions to geographical production. In this article, we present two sections. The first analyzes the trajectories of work on the spatiality of blacks in the production of socio-spatial segregation in São Gonçalo - a
\end{abstract}

\footnotetext{
${ }^{1}$ Professora Titular da UERJ, Centro de Formação Professores, São Gonçalo. E-mail: catia.antonia@ gmail.com; ORCID: https://orcid.org/0000-0002-2304-0131
} 
peripheral municipality in the metropolis of Rio de Janeiro. In the second section, he presents the author's reflective considerations about the black social movement, using philosophical tools to understand the forms of resistance in urban and societal contexts.

Keywords: socio-spatial segregation, Geography, black power movement, City

\section{ANDRELINO CAMPOS - DEL QUILOMBO A LA FAVELA, DEL ESPACIO PERIFÉRICO SEGREGADO A LA TEORÍA DEL SUJETO Y EL ANÁLISIS DEL LUGAR DEL NEGRO EN LA SEGREGACIÓN SOCIALMENTE INDUCIDA}

Resumen: Este artículo contribuye a través de la reflexión sobre los estudios del geógrafo brasileño Andrelino Campos, que era profesor adjunto en el Departamento de Geografía de la Facultad de Educación Docente de la Universidad Estatal de Río de Janeiro. Brasileño, negro y de la clase popular, fue un gran investigador. Académico, estudioso y muy creativo, tenía la sabiduría de los maestros y la capacidad de observar y trabajar muy raramente en la academia. Me considero un gran pensador de los tiempos actuales e hice grandes contribuciones a la producción geográfica. En este artículo, presentamos dos secciones. El primero analiza las trayectorias de trabajo sobre la espacialidad de los negros en la producción de segregación socioespacial en São Gonçalo, un municipio periférico en la metrópoli de Río de Janeiro. En la segunda sección, presenta las consideraciones reflexivas del autor sobre el movimiento social negro, utilizando herramientas filosóficas para comprender las formas de resistencia en contextos urbanos y sociales.

Palabras clave: segregación socioespacial, geografía, movimiento negro, ciudad.

\section{ANDRELINO CAMPOS - DU QUILOMBO À LA FA VELA, DE L'ESPACE PÉRIPHÉRIQUE SÉGRÉGÉ À LA THÉORIE DU SUJET ET À L'ANALYSE DE LA PLACE DU NOIR DANS LA SÉGRÉGATION SOCIALEMENT INDUITE}

Résumé: Cet article contribue à la réflexion sur les études du géographe brésilien Andrelino Campos, qui était professeur auxiliaire au Département de géographie de la Faculté de formation des enseignants de l'Université d'État de Rio de Janeiro. Brésilien, noir et issu de la classe populaire, il était un grand chercheur. Savant, studieux et très créatif, il avait la sagesse des maîtres et la capacité d'observer et de travailler très rarement à l'académie. Je me considère comme un grand penseur de l'époque actuelle et j'ai apporté une grande contribution à la production géographique. Dans cet article, nous présentons deux sections. Le premier analyse les trajectoires de travail sur la spatialité des noirs dans la production de ségrégation socio-spatiale à São Gonçalo - une municipalité périphérique de la métropole de Rio de Janeiro. Dans la deuxième section, il présente les réflexions de l'auteur sur le mouvement social noir, en utilisant des outils philosophiques pour comprendre les formes de résistance dans les contextes urbains et sociétaux.

Mots-clés: ségrégation socio-spatiale, géographie, mouvement noir, ville.

\section{INTRODUÇÃO}


A nossa amizade começou em 1999, quando juntos realizamos o concurso público para a cadeira de Geografia Urbana na UERJ. Já conhecia Andrelino nos anos anteriores na Universidade Federal do Rio de Janeiro. Sua dissertação intitulada "Do quilombo à favela: o tráfico de drogas enquanto estratégia de sobrevivência nos marcos de uma ordem segregacionista", em 1998, no programa de Pós-Graduação em Geografia pela Universidade Federal do Rio de Janeiro, sob a orientação do professor Marcelo Lopes de Souza, Andrelino, trouxe na década de 1990, o desafio em problematizar nos contextos urbanos a questão racial no contexto da Geografia.

Mas tarde sua dissertação foi publicada no formato do livro intitulado: Do Quilombo à favela: a produção de "espaço" criminalizado no Rio de Janeiro.

Na sua tese de doutorado, realizada no mesmo Programa de Pós-graduação em Geografia na Universidade Federal do Rio de Janeiro, defendeu a tese sob o título: “O planejamento urbano e a "invisibilidade" dos afrodescendentes: Discriminação étnico-racial, intervenção estatal e segregação socioespacial", no ano de 2005. As questões sobre o planejamento urbano, segregação socioespacial, discriminação racial, questão negra; mito fundador no contexto da metrópole do Rio de Janeiro.

Desse modo, os estudos e orientações de Andrelino sempre foram, com ênfase em Geografia Urbana, nos seguintes temas: questões étnico-raciais, discriminação/preconceitos, planejamento urbano, segregação socioespacial, sobretudo com espaços favelados na cidade do Rio de Janeiro. Foi responsável pela disciplina: História do Pensamento Geográfico desde 2000; no momento desenvolve suas pesquisas junto ao grupo que coordenava: o Núcleo de Estudos Sociedade, Espaço e Raça, na Faculdade de Formação de Professores da Universidade do Estado do Rio de Janeiro. Sempre rodeado de muitos alunos, participava do Programa de Pósgraduação em Geografia do Departamento de Geografia da FFP, onde ministrava disciplinas na graduação.

A sua trajetória acadêmica contribuiu com um olhar sensível em ouvir o outro e produziu uma reflexão minuciosa sobre a questão do negro no urbano que merece ser estudado melhor a sua contribuição na Geografia urbana. Sua dissertação, depois já publicada no formato de livro, em 2005, pela editora Bertrand Brasil, foi um marco importante na problemática urbana que Andrelino passa a desvelar. Nos anos 1990, não era comum a problematização das lutas contra as formas de dominação e de políticas públicas que seguem modelos racistas e de estereótipos dos pobres. 
A problemática fundiária, tais como as remoções das favelas, a partir dos anos 1960, incomodavam Andrelino quando começou a aprofundar a análise sobre o modelo social e político pautado na discriminação e, portanto, de sociedade e do território construídos com bases moral, política e econômica no processo colonizador e na escravidão. Para Andrelino, o conceito de quilombo é abrangente e refere-se aos espaços de resistências, de construção de comunidades e de vínculos sociais e sociabilidades com referências culturais ancestrais afrodescendentes. Lugares que podem ser desde os refúgios até os espaços precarizados e os de processos históricos de falências de fazendas oriundas das crises dos períodos colonial e imperiais. Para Andrelino, que pensava o presente, o quilombo é espaço de resistência ao senhoriato e ao Estado colonial. É forma-conteúdo que dá origem, de certa forma, também às favelas, por ser espaços segregados e estigmatizados.

Problematizar as políticas de habitação e as políticas urbanas, em geral, por meio da análise das estratégias e modelo de planejamento urbano, foi um recorte analítico muito importante e novos estudos da Geografia Urbana.

Andrelino chama a atenção para a construção das fronteiras sociais em contextos urbanos, onde a produção da favela é igualmente elaborada como os quilombos, lugares de desconfiança preconceito e a segregação estão interligados, mas têm características diferentes. Enquanto o primeiro faz parte de um sistema simbólico, de um imaginário, o segundo é o meio pelo qual essas ideias se materializam. Ele ressalta como é complexo o problema da segregação no Brasil, pois negros e brancos estão juntos, mas ao mesmo tempo separados, social e economicamente, sobretudo pelo somatório de estigmatização como negro, favelado, pobre - uma junção de estereótipos que acaba por acentuar sua condição de subalternização (2014). Segundo Andrelino, as dificuldades encontradas pelo negro hoje são decorrentes tanto do preconceito criado no tempo da escravidão, quanto da segregação causada por este preconceito, agravados pela ausência de políticas públicas visando compensar os anos de exploração dos negros. Ele explica que o processo de abolição brasileiro tem um grande peso no quadro atual de exclusão, pois nele os escravos foram libertos, mas não tiveram nenhum tipo de apoio por parte do governo, o que fez com que muitos passassem a viver na pobreza extrema. Dados do IBGE mostram que os descendentes de escravizados são a grande maioria dos que se encontram em situação de maior vulnerabilidade social, devido ao precário acesso à educação, saúde, mercado de trabalho etc. "Os pretos foram os últimos a ingressarem no sistema de educação, possibilitando um atraso considerável em relação ao grupo hegemônico 
da sociedade. Então, não tenhamos dúvidas, para a redução da pobreza serão necessárias muitas ações de compensação social" - alerta o professor Andrelino em entrevista (CAMPOS, 2005b).

Um dos aspectos mais visíveis da exclusão e da segregação são as favelas do Rio, cuja população é, em sua maioria, composta por descendentes de escravizados. Para Andrelino, a favela é um espaço excluído, assim como eram os quilombos, vítima de uma forte repressão do estado, que trata as comunidades como "espaços criminalizados" onde todos são suspeitos até que se prove o contrário". A segregação socioespacial é parte visível do estigma da discriminação e do preconceito contra a população das favelas que, em sua maioria, é constituída de pretos e pardos. Desta maneira, construímos um triplo preconceito, o de "cor", o "espacial" e de "pobreza". Continua dura a vida de favelado, como era muito dura a vida de quilombola." - Afirma o professor.

Este artigo tem como finalidade apresentar duas linhas de reflexão, dentre tantas outras, produzidas por Andrelino Campos, entre 2005 e 2018. Não seguiremos uma linha do tempo histórico, mas recorremos a explicação dessas linhas para melhor compreender a complexidade do pensamento do professor e pesquisador em Geografia. A primeira linha, tem origem em sua dissertação e que se refere à problemática da compreensão do negro na produção da segregação socioespacial induzida pelo Estado e pelas elites dominantes. A segunda linha, o autor analisa o sujeito social, com ênfase na compreensão do movimento negro, ocasionando importante contribuição para o entendimento do sentido de ação de resistência.

\section{DO QUILOMBO A FAVELA, DO ESPAÇO SEGREGADO À TEORIA DO SUJEITO}

A problemática étnico-racial relaciona-se com as formas de segregação e criminalização e com a produção social da cidade se mantém com centralidade nas preocupações de Andrelino. Sua preocupação foi debruçar-se sobre às questões da geografia do presente e questionando a questão da pobreza e a produção do imaginário dominante em relação dos negros nas favelas e periferias urbanas.

A produção de Andrelino, geralmente, desenhou as seguintes linhas: a primeira se refere ao mapeamento da segregação residencial e pobreza dos negros na Região metropolitana do Rio de Janeiro e a segunda consiste na análise teórica do movimento negro e 
da contribuição desse movimento para pensar as formas de resistência frente à segregação socioespacial. A seguir essas linhas:

(I) A preocupação com os limites dos estudos sobre planejamento urbano, política pública e a produção da cidade, disseminando os espaços segregados, espaço de concentração dos pobres e negros na cidade. Assim, o autor passa a estudar o urbano-metropolitano do Rio de Janeiro - que aparece na dissertação e continua no estudo da tese de doutorado, intitulada: O planejamento urbano e a "invisibilidade" dos afrodescendentes: Discriminação étnicoracial, intervenção estatal e segregação socioespacial, finalizado em 2006, pela UFRJ. Além da tese, Campos escreveu vários artigos, analisando o contexto da cidade do Rio de Janeiro e, destacamos o artigo “A sociedade do improviso gera intervenções urbanas provisórias: algumas considerações sobre aa expansão da cidade do Rio de Janeiro sob a ótica dos grupos segregados”, publicado no livro Metrópoles em mutação: dinâmicas territoriais, relações de poder e vida coletiva, organizado por mim e por Andrelino Campos, em 2008, pela Editora Revan com apoio da FAPERJ. Esse livro é resultado do II Seminário Nacional Metrópole: Governo, Sociedade e território: participação social e dinâmicas espaciais e o II Colóquio Internacional Metrópoles em Perspectivas: Globalização, território e conflitos na produção urbano-metropolitana e experiências de participação social, ocorrido na UERJ, em 2007. O evento contou com a brilhante participação na sua organização da Professora Ana Clara Torres Ribeiro que desde sua primeira edição (2003) dos eventos vinha contribuindo na formulação filosófica e metodológica dos eventos.

Recentemente a compreensão da relação da questão racial com a produção urbana se mantém em direção da compreensão da metrópole do Rio de Janeiro, sobretudo, na compreensão dos municípios do Leste metropolitano do Rio de Janeiro. Com isso, Andrelino elabora o projeto de pesquisa intitulado: "OS PADRÕES DE SEGREGAÇÃO NO PROCESSO DE METROPOLIZAÇÃO DO ESTADO DO RIO DE JANEIRO: "DESVENDANDO" AS QUESTÕES ÉTNICO-RACIAIS E SÓCIO-ESPACIAIS NO LESTE METROPOLITANO DO RIO DE JANEIRO” (entre 2011 e 2018) e passa a ser atualizado, em diferentes momentos, aprofundando metodologicamente a análise. Este projeto ressalta que os espaços segregados são induzidos pelo modelo de política urbana e busca analisar o urbano do Leste Metropolitano do Rio de Janeiro, composto pelos municípios de Niterói, São Gonçalo, Maricá, Itaboraí, Rio Bonito, Tanguá e Cachoeira de Macacu com população estimada de mais de dois milhões de habitantes. O autor assinala os discursos de 
modernidade se coadunam com as práticas de modernização dos espaços urbanos, grandes projetos convivem economias tradicionais; populações vivem em loteamentos sem regularização legal, ou loteamentos regulares ou em pequenas e grandes favelas entrecortados por conjuntos habitacionais. A centralidade do recorte espacial do Leste Metropolitano do Rio de Janeiro foi feita no município de São Gonçalo. Uma das principais fontes foi o IBGE, com análise do Censo demográfico de 2010, investigou, principalmente, a produção de espaços segregados intramunicipal do Leste Fluminense. Neste sentido, o objetivo principal do projeto foi analisar a espacialização dos autodeclarados da cor ou raça preta ou parda nos municípios que compõem o Leste Metropolitano do Rio de Janeiro, exceto a cidade de São Gonçalo, verificando ainda as condições de domicílios (renda, situação de loteamentos regulares, favelas, loteamentos sem a regulação do Estado), educabilidade, população ocupada entre outras variáveis. Como já anunciado, os procedimentos metodológicos propostos por Andrelino Campos têm como corte principal os dados estatísticos do IBGE, as visitas aos campos de estudos e pesquisas e a revisão de literaturas pertinentes ao espaço urbano, espaço segregados, questões étnico-raciais entre outros temas que emolduraram a pesquisa. Dentre artigos publicados e outras publicações e orientações como resultados destacamos três produtos importantes: (i) ATLAS DO LESTE METROPOLITANO DO RIO DE JANEIRO: Diagnóstico socioespacial dos municípios vistos pelo lado de cá da Baía de Guanabara, publicado entre 2018 e 2019, pela editora da Faculdade de Formação de Professores da UERJ. Trata-se de uma publicação com 350 páginas com gráficos, mapas e análises em que Andrelino Campos, em parceria com os professores Prof. Dr. Vinicius da Silva Seabra, Prof. Dr. Nilo Sergio d'Ávila Modesto e Profa. Dra. Catia Antonia da Silva e com apoio fundamental dos estudantes Hebert Guimarães Calvosa, Diogo Schott Heizer Alencar, Graciano Lourenço, Diogo L. dos Santos, Guilherme Café, Lucas dos Santos, vinculados ao seu grupo de pesquisa OBGEO-LMRJ. (ii) O segundo produto do projeto é a criação de forma mais estruturada, com apoio da Fundação Carlos Chagas Filho de Apoio a Pesquisa FAPERJ, do Núcleo de pesquisa e de extensão, intitulado Observatório Do Leste Metropolitano do Rio de Janeiro - OBGEO-LMRJ. Este Observatório estava ganhando robustez ao preparar materiais didáticos (teóricos, metodológicos) para a graduação e Pósgraduação em Geografia. E mais: Andrelino Campos passa a se preocupar com o papel da escola pública, da educação e do ensino de Geografia no desvendamento da segregação urbana e seus impactos na vida dos negros e negras. Desse modo, elabora um projeto com o 
mesmo título: Observatório Do Leste Metropolitano do Rio de Janeiro e recebeu apoio da FAPERJ, junto ao edital Escola Pública. Os mapas, gráficos e tabelas foram organizados por materiais didáticos e trabalhado por doze meses nas escolas. Como objetivo junto ao ensino teve como foco:

Identificar, compreender e analisar os indicadores que possam desvendar o Leste Metropolitano do Rio de Janeiro no que se refere: distribuição da população, às condições de habitabilidade, educabilidade, empregabilidade (condição de trabalho da população, incluindo, por exemplo, a pesca artesanal e atividade agrícola), segurança pública ), emprego de novas tecnologias localização e avaliação de equipamentos públicos infraestrutura saneamento urbana, condições de mobilidade urbana uso e cobertura do solo urbano e a estrutura de poder dos entes do LMRJ com intuito de produzir cartografias da segregação negra, e ainda., decorrente dos temas abordados, produzir materiais didáticos, experimentais (CAMPOS, 2019, p. 4).

O projeto foi implementado no Colégio Estadual Trasilbo Filgueiras, no bairro Jardim Catarina, São Gonçalo - RJ. O bairro construiu-se historicamente, como periferia da metrópole, por meio da implementação de loteamentos clandestinos nos anos de 1970 e 1980 , no contexto de metropolização fluminense e da expansão da periferização do município de São Gonçalo.

O desvendamento proposto por Andrelino é de grande relevância para o campo da Geografia urbana porque vem problematizar novos olhares e a destrinchar o que significa o modelo de produção da cidade, negando espaços e, portanto, mantendo nas políticas públicas, a estratégia de negação dos sujeitos e dos espaços e ao mesmo tempo, produzindo estereótipos e preconceitos aos moradores de favelas e da periferia. A escolha de estudar mais detalhadamente o Leste metropolitano deve-se sobretudo a falta de estudos nessa região da metrópole fluminense. O destaque ao estudo de São Gonçalo, deve-se a ao fato de que esse município atinge em 2010 um milhão de habitantes, num contexto de mais de $80 \%$ dos domicílios sem saneamento básico, coleta de lixo, asfaltamento precário. Um município que embora tenha importância econômica sendo um dos 10 municípios de maior arrecadação municipal e de produto interno bruto, o processo de segregação é muito acentuado (Mapa 1). 
Mapa 1 - Municípios do Leste Metropolitano do Rio de janeiro, por rendimento nominal médio mensal das pessoas de 10 anos ou mais de idade -

2010

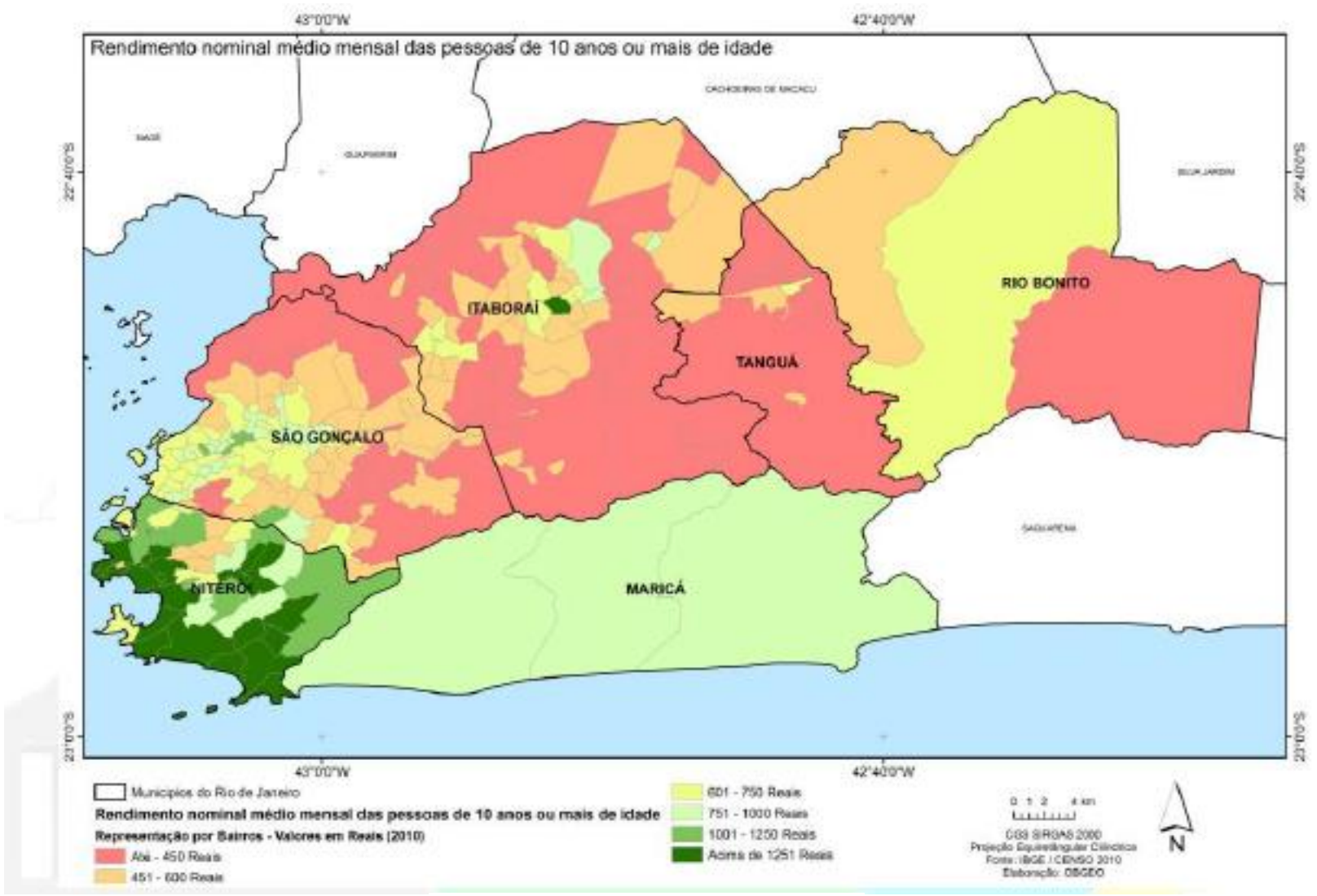

Fonte: CAMPOS, A. (2018-2019).

Ao analisar os municípios, Campos reconhece que a pobreza em São Gonçalo tem forte recorte étnico-racial, conforme observa-se no Gráfico 1. 50\% da população do leste metropolitano está no município de São Gonçalo, atingindo mais de um milhão de habitantes em 2010. Dentre os 50\%, cerca de 30\% são autodeclarados negros e pardos. 
Gráfico 1 - Quadro comparativo da autodeclaração da população, segundo Censo Demográfico do IBGE - 2010 - Municípios do Leste Metropolitano Fluminense

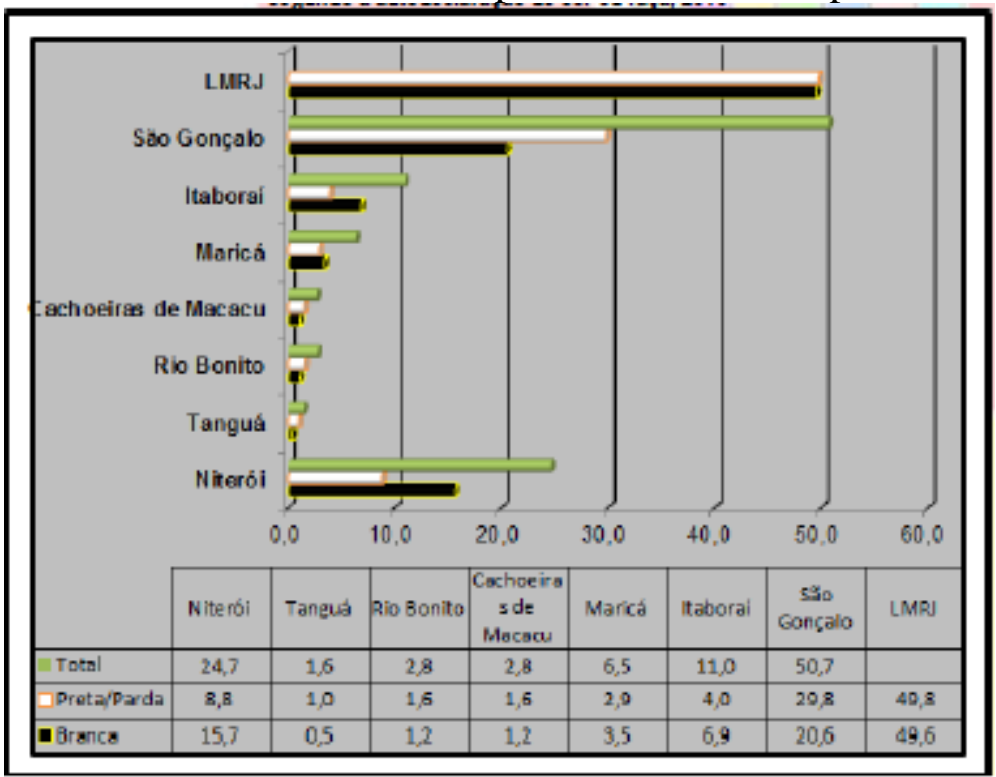

Fonte: CAMPOS, A. (2018-2019).

Quando os dados de autodeclaração (Gráfico) cruzado com os dados de renda (Mapa 1), observa-se a concentração relativa de população de baixa renda no município, ficando, em 2010, abaixo do valor do salário mínimo anual ( $\$$ 510,00), diferente, por exemplo do município vizinho Niterói, que historicamente (até 1975), foi capital fluminense e possui número de população de classe média, predominante branca que conforme aparece no mapa e gráfico.

(II) É importante ressaltar que a outra linha de reflexão de Andrelino dialoga com a disciplina que ministrava como História do Pensamento Geográfico, na graduação e Geografia e Relações de Poder no programa de Pós-graduação em Geografia (FFP-UERJ), bem como nas disciplinas de orientação de monografia. Trata-se da busca pela compreensão da produção do imaginário e dos sujeitos subalternos em contextos de "segregação espacialmente induzida". Elaborou o projeto de investigação intitulado: DESVENDANDO A SEGREGAÇÃO SOCIOESPACIALMENTE INDUZIDA E O IMAGINÁRIO DA VIOLÊNCIA URBANA EM SÃO GONÇALO, que buscava analisar os discursos do Estado e do senso comum, sobre a problemática da pobreza e da violência policial no município de São Gonçalo.

Citação do autor sobre o desafio temático: 
A emergência das Unidades Polícia Pacificadora implementado na capital do estado do Rio de Janeiro agravou, de certa forma esta percepção. Falsa? Verdadeira? Não sabemos. A situação, de certa maneira, levou a população a pensar que os grupos sociais mais pobres habitavam territórios e a população de forma geral localizava-se em bairro, implicitamente tornava-se sinônimo de lugar. Os discursos proferidos pelas autoridades, ao longo dos anos de 2008 e os anos seguintes, aumentou a sensação de segurança na capital, porém ampliou a sensação de insegurança nas cidades periféricas, como no leste metropolitano e, especialmente, em São Gonçalo, foco desta pesquisa. A criminalidade, parte constituinte da violência urbana é um dos vetores mais observado e difundido pela mídia local aumentando o imaginário de violência urbana nas cidades que compõem a estrutura metropolitana. Entretanto, temos fortes suspeitas que esta violência urbana apontada nos órgãos de imprensa, parcialmente é falsa, pois a criminalidade, apesar de trágica, pode ser produzida localmente. Tese está difícil de ser comprovada, sendo mais aceitável do ponto de vista do senso comum, acolher a ideia de ser importada da capital, como uma fuga em massa de procurados pela justiça, sobretudo aqueles ligados ao tráfico de drogas, para as cidades periféricas. Neste sentido, a violência urbana e o imaginário de violência em espaços segregados foco principal desse estudo, não é um tema fácil de ser enfrentado sem que tenhamos que desenvolver preconceitos na conformação de opiniões pessoais. Assim, buscar informações sistematizadas sobre a segregação e a produção de notícias sobre violência urbana possibilita minimamente esforços de separação daquilo que realmente acontece nestas cidades, separando das pechas que criam estigmas, discriminação e preconceitos (Curriculum lattes de Andrelino Campos, CNPq, disponível em http://lattes.cnpq.br/7464184670798122, coletado em 2020).

Na reflexão alguns conceitos são estudados: imaginário social, sujeito, indivíduo, pessoa, movimento social negro. Nesse sentido, destaca-se o artigo “ Particularidades do movimento negro enquanto sujeito da história brasileira, publicado no livro Cartografia da ação e movimentos da sociedade: desafios das experiencias urbanas, organizado por Catia Antonia da Silva, Ana Clara Torres Ribeiro e Andrelino Campos (2011), editora Lamparina). O livro é composto por artigos criados e inspirados no seio de debates, reflexões e estudos apresentados durante os eventos: III Seminário Nacional "Metrópole, Governo, Sociedade e Território" e II Colóquio Internacional metrópoles em perspectivas, ambos ocorreram de 2010, na Faculdade de Formação de Professores da Universidade do Estado do Rio de Janeiro e tiveram como tema central Território usado e cartografia da ação: por outra gestão urbanometropolitana. Nesse artigo, Campos ressalta a formação do sujeito no contexto dos movimentos sociais urbanos, sobretudo o sujeito negro. Para o autor, o Ser negro, branco, indígena não cobre a universalidade do fenômeno de homem ou mulher, ou ainda criança. A contribuição do autor está na análise de que o movimento que acompanha do nascimento passando pela vida até a morte é inexorável, da mesma forma as transformações do ser se produz por muitas trajetórias, particularidades e multiplicidades de sentidos. 
Afirma: (...) Não nascemos pessoa ou sujeito, nascemos indivíduos humanos, nos tornamos parte do sujeito que é coletivo, ele se faz pela história por meio de projetos que conjunto traça para si e a para a sociedade que pretende. Compreender esta dimensão da vida é compreender que a sociedade é uma arena em constante disputa, pois somos constituídos de diferentes interesses e psiques. Entendemos que tratar a diferença é fundamental e saudável para qualquer sociedade, visto que nascemos diferentes e nos tornamos parte de sujeitos também diferentes. Se assim é verdade, então a universalidade também se constitui de sujeitos diferentes. Como vimos, o negro se constitui como um dos sujeitos legítimos da sociedade brasileira, não reconhecer esse fato é ignorar a própria história nacional. São pessoa-para-si que se tornam pessoa-para-o-outro e constroem a vida desde muito tempo. Demonstrou-se ao longo deste ensaio, que a melhor maneira de aprendermos o sujeito é na particularidade. Se negarmos as evidências, criamos falsas verdades, tentando homogeneizar aquilo que por essência é outro. Neste sentido, por mais próximo que estejam os grupos que buscam justiça, superação da sociedade hierarquizada produtora de heteronomia, há sempre muita discrepância e diferença no tratar de si e do outro (CAMPOS, 2011, p. 168).

$\mathrm{O}$ autor elabora reflexão importante, incluindo o movimento da sociedade e o movimento da história, em que apesar das diferentes lutas com participação dos negros, nem todos os movimentos, apesar de serem legítimos e tendo negros como participantes não constituía necessariamente um movimento negro, embora acabe por contribui nas lutas sociais contra as formas de segregação, de criminalização e de todas as formas de violência urbana.

Desse modo, Andrelino reconhece, teoricamente, que o conceito de sujeito é importante e deve ser compreendido como portador de transformação histórica, quer seja coletivo, quer seja individual e de pessoa. Faz uma análise minuciosa na construção do conceito de sujeito recorrendo aos autores, principalmente, CASTORIADIS, 1986; ELIAS, 1994, LUKÁCS, 1970.

Para Campos (2011) Castoriadis tem centralidade em sua reflexão ao reconhecer que na instituição do imaginária da sociedade a dimensão do tempo produz o movimento de esquema da sucessão da transformação do indivíduo (quando nasce), passando pela construção da pessoa (pessoa-em-si e pessoa para o outro), até ocorrer o envolvimento no sentido da ação coletiva na construção ativa - a construção do sujeito. Assim, diz o autor: "Castoriadis nos dirá que: “(...) o que se dá em e pela história não é uma sequência determinada do determinado, mas emergência radical, criação imanente, novidade não trivial. É isto que manifestam tanto a existência de uma história in tato, como aparecimento de novas sociedades" (Castoriadis, id. ibid. p. 220) [e de novas pessoas e a fabricação também de novos indivíduos. A sucessão enquanto processo temporal é responsável pela história das pessoas em suas singularidades. Essa possibilidade que permite ao autor afirmar que ela (história) não pode (e nunca será) uma repetição. É essa dimensão da história que a um só tempo permite a sua existência e a dimensão da simultaneidade (2011, p. 169). 
Reafirmando a importância filosófica da construção do sujeito, Andrelino Campos articula a reflexão e consegue fazer uma construção teórica do sujeito e da corporeidade - sobretudo do sujeito individual na construção do sujeito coletivo articulado à compreensão do sentido da ação. Sentido este construído na produção de uma espacialidade do corpo.

Nas palavras do autor:

(...) Esse sentido de corporeidade diz respeito ao movimento desde indivíduo humano à pessoa-para-si-, contemplando a relação em todas as dimensões. Cada família, cada escola, cada empresa, cada movimento social (sindicatos, movimento social contra a propriedade rural e/ou urbana, associações de vários matizes etc.) têm histórias e lugares ditados pela pessoa-para-o-outro em reunião, mas nem todos os grupos se constituem em sujeito do conhecimento e da história. É continente que tenham projetos, nos termos como nos ensina Castoriadis (1986, pp. 89-98) que pessoa-parao-outro se reúnam para alcançar um dado objetivo e que seja historicamente demarcado pela ação (CAMPOS, 2011, p. 169).

Assim, Andrelino realiza a reflexão teórica a respeito dos movimentos dos corpos (trajetórias, sociabilidades, memórias e vínculos sociais) desde a casa à sociedade. Traça a argumentação sobre movimentos sucessivos de cada pessoa-para-si e torna-se movimento pessoa-para-o-outro, que para o autor significa simples sucessão de tempo, história/espaço/lugar singulares, ou seja, o estado de reunião, é (...)“a simultaneidade espaço/tempo, possibilidade de encontros onde ocorre a história de alguém em dado lugar. Os deslocamentos e sociabilidades no trabalho, na rua, nos múltiplos encontros societários produzem a reunião de múltiplos tempos/espaços e de múltiplas pessoas-para-si, tornando-se na reunião pessoa-para-o-outro" (...) (CAMPOS, 2011, P. 168), onde o esquema da sucessão torna-se em esquema da simultaneidade, e o lugar pode, pelo movimento, pelas questões postas, pelas formas de dominação e de resistência sofrer o processo alteração-transformação de permanecer como lugar, ou o lugar ser parte constituinte de estruturas maior do que a pessoa. Desse modo, pode ou não nascer o sujeito porque no movimento de mudança faz parte de conjunto de transformações fora da pessoa, a transformação em si, por si, o dialogo da corporeidade com a consciência sobre os problemas que vive no lugar, de um território, de uma região. Reconhece o autor que nesse mesmo sentido, “a dimensão espacial, também em movimento, transforma-se, mesmo que seja apenas pelas mudanças de lugares, visto que cada pessoa-para-si tem história e lugar singular” (2011, p. 174). 
Outrossim, a problemática do movimento negro para Andrelino Campos, precisa ser pensada dentro da afirmação filosófica e reconhecer que as tendências de homogeneidade produzidas pelas narrativas são perigosas porque não reconhecem as trajetórias do indivíduo ao sujeito e perdem de vista as particularidades quer seja dessas trajetórias tempo-espaço, quer seja do sentido das ações. São perigosas, quer seja no imaginário dominante e conservador, quer seja no âmbito das lutas e resistências. O movimento social precisa reconhecer a dialética entre a universalização e a particularidades dos sujeitos, sejam eles concebidos como personas.

Expressa o autor:

Todos os movimentos sociais, todas as mulheres, todos os homens, todos os homens, todos os estudantes, todos os professores, todas as escolas, são fatos universais que não há como determinar nem lugar, nem história. Nesse caso, o sujeito é difuso, por isso, o conhecimento produzido também é difuso. Entretanto, o movimento de negros(as), as mulheres sem-tetos do Rio de Janeiro, os professores públicos de Araruama, os alunos das escolas públicas de Vassoura constituem algumas particularidades que não repetem em parte alguma. Alguns elementos da universalidade, como o caso dos movimentos sociais são transferidos dessa à particularidade (e vice-versa). Contudo, outros elementos são retidos ao nível são da particularidade. Nesse sentido, o pensar pessoa-para-si em movimento para a reunião com pessoa-para-o-outro permite que as diferentes associações não se repliquem, visto que os grupos constituem metas distintas para viabilizar a sua reunião.

Outrossim, o autor problematiza o movimento social e reconhece as lutas existentes fora das entidades de classe, fora dos sindicatos e fora das associações também como movimentos sociais, por isso afirma que são movimentos difusos e que não é contraditório o reconhecimento das particularidades das ações e dos sujeitos das ações. Perfilha a luta do povo negro nos movimentos de gênero, nas lutas dos trabalhadores urbanos e rurais, nas lutas pelas moradias, na organização social e políticas dos bairros negros (JUNIOR; 2019) dentre outras lutas e reivindicações. E vê nos movimentos que tiveram negros e negras como sujeitos ativos e com causas étnico-raciais como a possiblidade necessária de manutenção das formas de resistências sem produzir um dilaceramento de lutas de grupos excludentes. Aliás, esse tem sido um dos maiores perigos na luta da esquerda no Brasil, a ser produzir negação entre os grupos sociais, em vez de produzir-se a soma das particularidades.

Finaliza o artigo com um parágrafo maravilhoso, aproximando o pensar filosófico ao empírico-histórico: 
Nesse sentido, muitas pessoa-para-si que se tornaram emblemáticas no contexto de pessoa-para-o-outro foram importantes para formar o sujeito do Movimento social Negro se tornaram sujeito da história, como, por exemplo: Ganga Zumba, Andalaquituche, Dandara, Acoitirene, Aqualtune Danbraganga, Zumbi (Cardoso, 2002, p. 65), Abdias Nascimento, Arthur Ramos, Arlindo Veiga dos Santos, Lélia Gonzales, Maria Beatriz Nascimento e tantos milhões de Pretos e Pretas: João(s), Marias, Josés, Cosmes de sobrenomes Silvas, Santos, Oliveiras, que lutaram, viveram, morreram e desapareceram ao longo desses 478 anos de combates $(1532$ - 2010) (CAMPOS, 2011, p. 179).

É complexo o pensamento de Andrelino Campos. Sua leitura de produção social da cidade também é complexa. Nessa segunda seção do artigo, a problemática do entendimento do movimento social negro com base na compreensão do sujeito, coopera para pensar as formas de resistências frente aos processos intensos de criminalização e de segregação dos negros residentes nas periferias e favelas. Para o autor, não se separa corpo e espaço - os estigmas são dos corpos e dos espaços, ao mesmo tempo. O torna fundamental compreender conceitualmente o sujeito e sua espacialidade e historicidade, e assim contribuir na libertação de corpos e espaços dos parâmetros hegemônicos e, socialmente perversos.

\section{CONSIDERAÇÕES FINAIS}

Sem dúvida é muito complexo o pensamento de Andrelino Campos. Suas reflexões geográficas, assim como do geógrafo Milton Santos, não perdem de vista o diálogo com a Filosofia e as Ciências Sociais. Seu trabalho intuitivo, reflexivo e analítico percorre vários autores. Muitas das conversas com a Professora e socióloga Ana Clara Torres Ribeiro, no debate sobre as teorias da ação, com o amigo Nilo Modesto sobre as práticas políticas e práticas sociais em São Gonçalo, os trabalhos compartilhados durante a participação de bancas de monografias, mestrados e doutorado, na participação como pesquisador associado nos meus projetos de pesquisa contribuiu muito com seu questionamento e conhecimento. Desse modo, foi militante do movimento negro dentro da academia e dialogava com essa militância com a teoria e o método em Geografia. Na verdade, às vezes o pensador e teórico Andrelino parecia fazer (psico) análise de seu próprio ser, sem nunca ter colocado explicitamente suas histórias pessoais. O pensador Andrelino, sempre sereno, mesmo quando sentia as dores no seu corpo, jamais deixou de transcender o sentido da vida e a importância da formação docente, dos estudos e sobretudo a atenção com o outro. 
Trago nesse ensaio o desafio de compreender a complexidade do pensamento de Andrelino no que se refere à questão étnico-racial e os contextos urbano-metropolitanos. Certamente que o autor percorreu por outros caminhos como a questão das cotas raciais na universidade e as questões da Lei 10.639/03, que tratava da obrigatoriedade do ensino da história e cultura afro-brasileira e africana em todas as escolas, públicas e particulares, do ensino fundamental até o ensino médio.

Falecido em 20 de maio de 2018. Foi sujeito ativista no âmbito da universidade e da divulgação da Geografia. Militou na luta dos negros e negras quando escreveu, orientou, denunciou em diversos jornais as formas de criminalização e de segregação e de violência sofrida pelos negros nas cidades, nas metrópoles, nas periferias e favelas.

Nesse artigo, buscamos apresentar algumas linhas sobre a produção intelectual de Andrelino Campos, sobretudo no que se refere à relação entre a produção da segregação na cidade e a questão racial negra. Na primeira seção, procuramos apresentar as trajetórias e esforços do autor em aprofundar a análise urbana, no contexto da metrópole brasileira e verifica a permanência das formas de exclusão e de desigualdades nos espaços segregados. Como afirma o autor trata-se de uma segregação socialmente induzida pelo modelo de políticas sociais e urbanas traçadas pelo Estado e as elites conservadoras. Sem dúvida, contribuiu intensamente para a compreensão das formas de dominação e da criminalização dos negros na cidade e para a reflexão crítica da produção social da segregação urbana. Entretanto, o autor, que nos orienta na teoria social crítica, não perde de vista que diante das formas de dominação estão postas as formas de resistência. A reflexão de Andrelino sobre o conceito de movimento negro enquanto movimento social - sujeito histórico particularidades para a compreensão das lutas frente aos modelos de produção da segregação socioespacial dos negros é poderá ser apropriado pelas novas gerações de professores e estudantes que vão propor novas questões no campo dos estudos urbanos. Desse modo, aprende-se com Andrelino desbravar novos caminhos e leituras de mundo que sejam críticas e libertadoras. Deixou um belo acervo e legado para seus orientandos que muito bem, souberam e sabem compreender e trabalhar. E todos e todas podemos aproveitar na construção coletiva do pensamento social e geográfico os ensinamentos do Doutor Andrelino Campos, sobretudo nos contextos de crise da COVID 19 em que seus impactos nos espaços segregados estão terríveis. 


\section{REFERÊNCIAS BIBLIOGRÁFICAS}

CAMPOS, Andrelino. Despolitização do discurso da segregação frente às políticas de planejamento urbano na metrópole. In: C. A. da Silva; D. G. Freire; F. J. G. de Oliveira. (Org.). Metrópole: governo, sociedade e território. 1ed.Rio de Janeiro: DP\&A Editora, 2006, v. 1, p. 171-192.

CAMPOS, Andrelino. A sociedade do improviso gera intervenções urbanas provisporias: algumas considerações sobre a expansão da cidade do Rio de Janeiro sob a ótica dos grupos segregados. In: SILVA, Catia Antonia da; CAMPOS, Andrelino (Org.). Metrópole em mutação: Dinâmicas territoriais, relações de poder e vida coletiva. 1ed.Rio de Janeiro: REvan/Faperj, 2008, v. 1.000, p. 81103.

CAMPOS, Andrelino. Entre a pessoa e o sujeito do conhecimento: Algumas considerações sobre o movimento negro no contexto socioespacial. In: Reinaldo José de Oliveira. (Org.). A cidade e o negro no Brasil: Cidadania e território. 1ed.São Paulo: Alameda Casa Editorial, 2013, v. 1, p. 231-266.

CAMPOS, Andrelino. Particularidade do Movimento Negro enquanto sujeito da história brasileira. In: SILVA, C. A. ; RIBEIRO, A. C. T.; CAMPOS, Andrelino. (Org.). Cartografia da ação e movimentos da sociedade. 1ed.Rio de Janeiro: Lamparina Editora, 2011, v. 1, p. 131-159.

CAMPOS, Andrelino. Questões étnico-raciais no contexto da segregação socioespacial na produção do espaço urbano brasileiro: algumas questões teórico-metodológicas. In: SANTOS, Renato Emerson dos. (Org.). Questões urbanas e racismo. 1ed.Petrópolis: DP et Alii Editora Ltda/ABPN/Ford Foundation/Oxfam, 2012, v. 1, p. 66-102.

CAMPOS, Andrelino. Quilombos, favelas e os modelos de ocupação dos subúrbios: Algumas reflexões sobre a expansão urbanas sob a ótica dos grupos segregados. In: JESUS, Regina de ARAÚJO, Fátima de; Mairce da Silva \& CUNHA JUNIOR, Henrique. (Org.). Dez Anos da Lei $n$ 10.639/03: Memória e perspectiva. 1ed.Fortaleza: Série Diálogo Interpositivo, 2013, v. 1, p. 243-267.

CAMPOS, Andrelino. As particularidades na formação de sujeitos na história socioespacial brasileira: algumas considerações sobre o Movimento Negro. REVISTA GEOGRAFARES, p. 21-48, 2011.

CAMPOS, Andrelino. Movimento em estruturas "socioespaciais": em busca dos sujeitos subalternos. In SILVA, Catia. CAMPOS, Aandrelino. MODESTO, Nilo. S. d'A. Por uma geografia das existências: movimentos, ação social e produção do espaço. Rio de janeiro, Consequência, 2014/FAPERJ, p. 47-66.

CAMPOS, Andrelino. A distribuição dos objetos geográficos e as suas representações espaciais. Revista Tamoios (Impresso), v. 1, p. 06-17, 2005.

CAMPOS, Andrelino. Afrodescendência e a superação do 'velho' conceito de raça. In: GONÇALVES, MARIA Alice Rezende. (Org.). Educação, cultura e literatura afro-brasileira Coleção Sempre Negro. 1ed.Rio de Janeiro: Quartet, 2007, v. 1, p. 79-108.

CAMPOS, Andrelino. Do quilombo à favela: A produção do espaço criminalizado no Rio de Janeiro. 3. ed. Rio de Janeiro: Bertrand Brasil, 2010. v. 500, 210 p.

CAMPOS, Andrelino. Escola pública: a neutralidade perdida em áreas de conflito tematizados. Anais do I Seminário de Educação Paulo Freire na Contemporaneidade, CD, 2001. 
CAMPOS, Andrelino. Origens, expansão e (des)construção do espaço favelado no Rio de Janeiro: a cidadania ausente. Rio Urbano: Revista da Região Metropolitana do Rio de Janeiro, Rio de Janeiro, p. $22-31,2002$.

CAMPOS, Andrelino. Os sistemas simbólicos e as representações socioespaciais no contexto do imaginário instituído da sociedade. Revista Fluminense de Geografia, v. 1, p. 3, 2006.

CAMPOS, Andrelino. Programa Favela-Bairro: a nova moradia pode estar em outra favela. Revista Fluminense de Geografia, Niterói, v. 1, p. 28-36, 1998.

CAMPOS, Andrelino.; SILVA JR, D. . Educação Pública: a competitividade pela rua, em temporada de crise estrutural. Revista Tamoios, Rio de Janeiro, v. 1, p. 9-19, 2001.

CAMPOS, Andrelino.; FRANCA, A. L. ; FERNANDES, F. M. . Entre indivíduo e sujeito: Lugares e territórios em movimento na metrópole. In: SILVA, Catia Antônia. (Org.). Território e ação social: sentido da apropriação urbana. 1ed.Rio de Janeiro: Lamparina Editora, 2011, v. 1, p. 131-150.

CAMPOS, Andrelino. Relatório FAPERJ: projeto: OBSERVATÓRIO GEOGRÁFICO DO LESTE METROPOLITANO DO RIO DE JANEIRO (OBGEO-LMRJ), São Gonçalo, 2019.

CAMPOS, Andrelino. Bate papo UOL com Andrelino campos - 2005b - disponível: http://tc.batepapo.uol.com.br/convidados/arquivo/livros/andrelino-campos-geografo.jhtm, acessado e, 08 de abril de 2020.

CAMPOS, Andrelino. et. al. ATLAS DO LESTE METROPOLITANO DO RIO DE JANEIRO: Diagnóstico socioespacial dos municípios vistos pelo lado de cá da Baía de Guanabara. São Gonçalo: UERJ/FFP, 2018-2019, 350p.

CASTORIADIS, Cornélio. A instituição imaginária da sociedade. Rio de Janeiro, Paz e Terra, 1986.

CARRIJO, Valéria L. A. "EMPODERA! Juventude Negra" e a pesquisa sobre processos de reexistência das juventudes negras, X CONGRESSO BRASILEIRO DE PESQUISADORES NEGROS SIMPÓSIO NACIONAL DE EDUCAÇÃO BÁSICA DA ABPN EIXO TEMÁTICO: JUVENTUDE NEGRA. Outubro de 2018, Uberlândia, 8p.

CHAUI, Marilena. Convite à filosofia. São Paulo: Ática, 1995.

CORRÊA, Roberto. L. Espaço Urbano. São Paulo, Ática, 1989.

ELIAS, Nobert. A sociedade dos indivíduos. Rio de Janeiro, Jorge Zahar, 1994.

GOMES, Ana C. da C., OLIVEIRA, Luciana R. Mulheres que educam: Movimento de Mulheres Negras - "o sim-lugar": religação, decolonialidade e construção de contra-poderes. X CONGRESSO BRASILEIRO DE PESQUISADORES NEGROS - SIMPÓSIO NACIONAL DE EDUCAÇÃO BÁSICA DA ABPN EIXO TEMÁTICO: JUVENTUDE NEGRA. Outubro de 2018, Uberlândia, 16p.

JUNIOR, Henrique Cunha. Bairros Negros: a foruma urbana das populações negras no Brasil. Revista da Associação Brasileira de Pesquisadores Negros (ABPN), v. 11. Número especial, p.65-86, maio 2019. ISSN 2177-2770. Disponível em: 〈https://abpnrevista.org.br/index.php/site/article/view/683>. Acesso em: 10 abril. 2020

LUKÁCS, György. Introdução a uma estética marxista. Rio de Janeiro: Civilização Brasileira, 1970. 
RATTS . Alex. Geografia, relações étnico-raciais e educação: a dimensão espacial das políticas de ações afirmativas no ensino. Terra Livre. Crise, práxis e autonomia: espaços de resistência e de esperanças. São Paulo/SP. Ano 26, v. 1, n. 34, jan-jun/2010. p. 125-140.

RIBEIRO, Ana Clara T. "Pequena reflexão sobre categorias da teoria crítica do espaço: território usado, território praticado" In SOUZA, Maria Adélia Aparecida de (org). Território brasileiro: usos e abusos, São Paulo: Edições Territorial, 2003.

RIBEIRO, Ana Clara Torres (org).El rostro urbano de América Latina, Buenos Aires: CLACSO, 2004.

RIBEIRO, Ana Clara T. et al - Relatório Técnico-Científico do Projeto: Cartografia da Ação e Análise de Conjuntura: reivindicações e protestos em contextos metropolitanos (quatro volumes), Programa Cientista do Nosso Estado, Rio de Janeiro: FAPERJ, 2005-2006.

SILVA, Catia. A. (Org.) ; RIBEIRO, Ana. C. T. (Org.) ; CAMPOS, A. (Org.) . Cartografia da ação e movimentos da sociedade. 1. ed. Rio de Janeiro: Lamparina, 2011. v. 1. 189p .

SILVA, Catia. A. (Org.) ; CAMPOS, Andrelino. (Org.) . Metrópole e Invisibilidades: Da política às lutas de sentidos da apropriação urbana. 1. ed. Rio de Janeiro: Lamparina Editora, 2015. v. 2500. 1p .

SILVA, Catia. A. (Org.) ; CAMPOS, Andrelino. (Org.) . Metrópole em Mutação: Dinâmicas territoriais, relações de poder e vida coletiva. 1. ed. Rio de Janeiro: Revan/Faperj, 2008. v. 1.000. 292p

SILVA, Catia. A. ; CAMPOS, Andrelino.; Modesto, Nilo. S. D'Ávila . Por uma geografia das existências: Movimentos, ação social e produção do espaço 64433076). 1. ed. Rio de Janeiro: Editora Consequência, 2014. 112p .

Recebido em: 22/09/2020

Aceito em: 30/10/2020 